\title{
Formation of the Donor-Acceptor Charge-Transfer Exciton and Its Contribution to Charge Photogeneration and Recombination in Small-Molecule Bulk Heterojunctions
}

\author{
M. J. Kendrick, ${ }^{\dagger}$ A. Neunzert, ${ }^{\dagger}$ M. M. Payne, ${ }^{\ddagger}$ B. Purushothaman ${ }^{\ddagger}$ B. D. Rose, ${ }^{\S}$ J. E. Anthony, ${ }^{\ddagger}$ \\ M. M. Haley, ${ }^{\S}$ and O. Ostroverkhova ${ }^{*} \dagger$ \\ ${ }^{\dagger}$ Department of Physics, Oregon State University, Corvallis, Oregon 97331, United States \\ ${ }^{\ddagger}$ Department of Chemistry, University of Kentucky, Lexington, Kentucky 40506, United States \\ ${ }^{\S}$ Department of Chemistry, University of Oregon, Eugene, Oregon 97403, United States
}

Supporting Information

ABSTRACT: We report on the formation of charge-transfer (CT) excitons and their effect on photocurrent dynamics in composites with a fluorinated anthradithiophene (ADT-TES-F) donor (D) and acceptors (A) with (i) various LUMO energy offsets with respect to that of the donor $(\triangle \mathrm{LUMO})$ and (ii) several different side groups that modify spatial D/A separation at the D/A interface. Exciplexes and nonemissive CT excitons were formed in composites with $\triangle \mathrm{LUMO}<0.6$ and $>0.6 \mathrm{eV}$, respectively. A competition between fast charge carrier photogeneration and $\mathrm{CT}$ exciton formation was observed, with outcomes depending on the applied electric field $(E)$ and on the D/A separation. At low $E$ fields, CT formation was dominant, and up to a factor of 2 increase in charge photogeneration efficiency due to $\mathrm{CT}$ exciton dissociation was observed in composites with large spatial D/A separation compared with that in pristine D films. At high $E$ fields, fast charge carrier photogeneration was dominant in all composites, and no improvement in charge photogeneration efficiency with respect to that in pristine D films was observed.

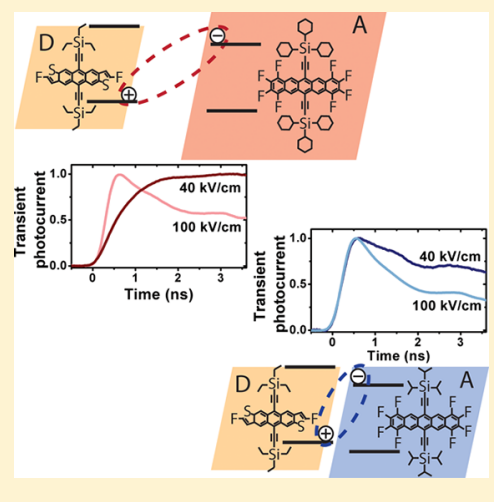
Dramatic changes in charge recombination dynamics were observed depending on the spatial D/A separation. These contributed to a factor of 5-10 improvement in continuous-wave photocurrents in composites with large spatial D/A separation as compared with those in pristine D films.

\section{INTRODUCTION}

Organic optoelectronic materials have drawn interest based on their low cost and tunable properties and have shown promise in a wide range of applications, from display technologies to photovoltaics. ${ }^{1,2}$ Additionally, solution-processable organics can be combined into composite materials, which can have drastically different optical and electronic properties and can be tailored for specific applications. For example, organic bulk heterojunctions (BHJs) have been utilized in solar cells, ${ }^{3}$ photodetectors, ${ }^{4}$ and photorefractive devices ${ }^{5}$ due to enhanced photogeneration of charge carriers that results from photoinduced electron transfer between donor (D) and (A) acceptor molecules with properly offset HOMO and LUMO energies. ${ }^{6}$ Currently, most high-performance $\mathrm{BHJs}$ are combinations of a photoconductive polymer donor with fullerene-based acceptors; however, the performance of small-molecule $\mathrm{BHJs}^{7-10}$ is rapidly improving, with several small-molecule-based materials exhibiting power conversion efficiencies (PCEs) of 6 to $7 \%{ }^{11,12}$

The relative HOMO and LUMO energies of the D and A and molecular packing at the $\mathrm{D} / \mathrm{A}$ interface have been identified as key factors in efficient charge photogeneration. ${ }^{6,13-19}$ However, the mechanisms driving the evolution of an exciton created by an absorbed photon in the donor to free charge carriers, especially those involving the formation of intermediate bound charge-transfer (CT) states shared between adjacent $\mathrm{D}$ and $\mathrm{A}$ molecules, and how they depend on the $\mathrm{D}$ and $\mathrm{A}$ HOMO and LUMO energies and molecular alignment at the D/A interface are still under investigation. ${ }^{6,17,20-24}$ In particular, the relationship between properties of CT excitons and photocurrent is not well understood ${ }^{6,17,25,26}$ and is important to address for the development of efficient BHJs. Most work aiming to quantify properties of CT states and their effect on the photoconductive performance of $\mathrm{BHJ}$ s has been done in polymer-based D/A systems, ${ }^{27-31}$ primarily polymer/ fullerene blends, ${ }^{32}$ whereas considerably less is known about similar issues in small-molecule BHJs. ${ }^{33-35}$ In this article, we explore the effects of (i) the offset in HOMO and LUMO energies of $\mathrm{D}$ and $\mathrm{A}$ and (ii) the molecular packing at the $\mathrm{D} / \mathrm{A}$ interface on CT state formation, exciton dynamics, and photocurrent in small-molecule BHJs. We show that the spatial $\mathrm{D} / \mathrm{A}$ separation at the $\mathrm{D} / \mathrm{A}$ interface plays a crucial role in the properties of CT states and their contribution to the photocurrent and that it dominates over effects of the $\mathrm{D} / \mathrm{A}$ LUMO energy offsets.

Received: June 15, 2012

Revised: July 30, 2012

Published: August 10, 2012 


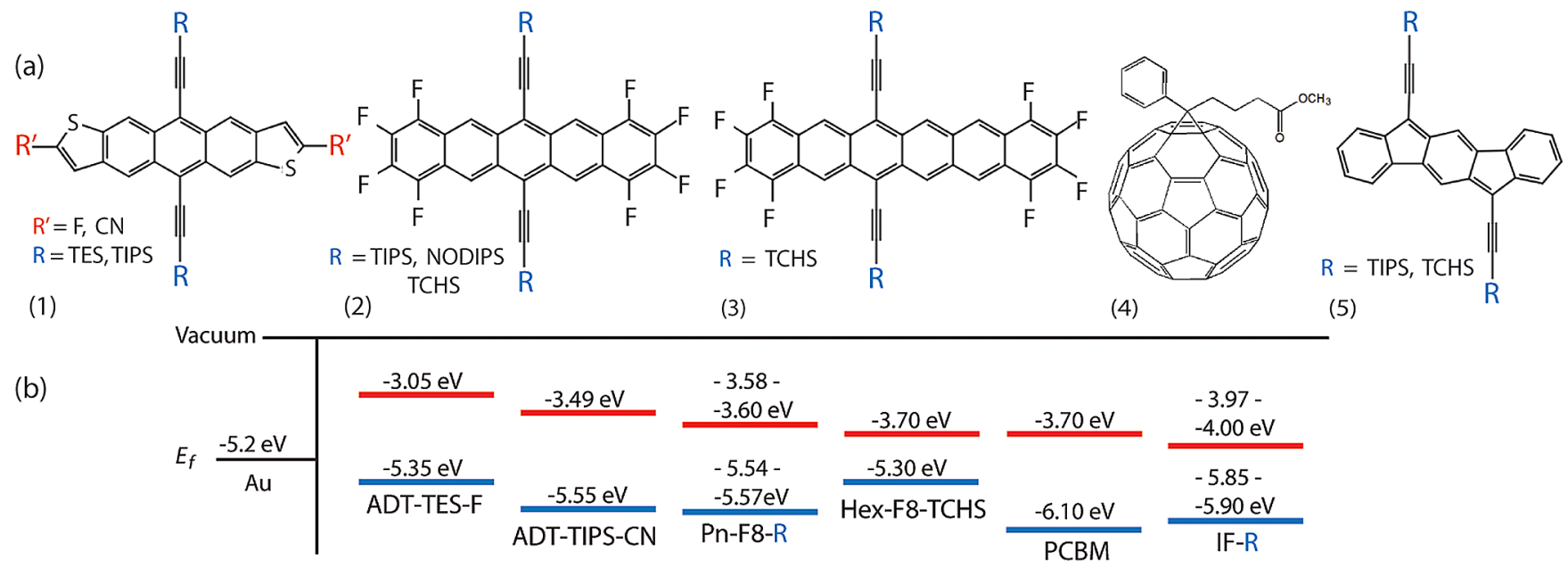

Figure 1. (a) Molecular structures of the donor (a.1, ADT-TES-F: $R=T E S, R^{\prime}=F$ ) and acceptors used in our studies: (a.1) ADT-TIPS-CN: R = TIPS, $\mathrm{R}^{\prime}$ = CN; (a.2) Pn derivatives; (a.3) Hex derivative; (a.4) PCBM; and (a.5) IF derivatives. (b) HOMO and LUMO energies of molecules under study.

Table 1. Electrochemical, Optical, and Photoluminescent Properties of Molecules

\begin{tabular}{lcccccccc}
\multicolumn{1}{c}{ molecule } & HOMO-LUMO gap $E_{\text {gap }}, \mathrm{eV}^{a}$ & $\lambda_{\text {abs }} \mathrm{nm}^{b}$ & $\lambda_{\mathrm{PL}}, \mathrm{nm}^{b}$ & $\mathrm{E}_{\mathrm{optgap}}, \mathrm{eV}^{c}$ & $\mathrm{E}_{\mathrm{DA}}, \mathrm{eV}^{d}$ & $\Delta G_{\mathrm{CT}}, \mathrm{eV}^{e}$ & $\Delta G_{\mathrm{ET}}, \mathrm{eV}^{f}$ & $\Delta G_{\mathrm{CT}}-\Delta G_{\mathrm{ET}}, \mathrm{eV}$ \\
ADT-TES-F & 2.3 & 528 & 536 & 2.31 & & & & \\
ADT-TIPS-CN & 2.06 & 582 & 590 & 2.1 & 1.86 & -0.45 & -0.21 & -0.24 \\
Pn-F8-NODIPS & 1.96 & 635 & 645 & 1.92 & 1.76 & -0.55 & -0.39 & -0.16 \\
Hex-F8-TCHS & 1.6 & 739 & 800 & 1.55 & 1.65 & -0.66 & -0.76 & 0.1 \\
IF-TIPS & 1.9 & 572 & & $1.77^{g}$ & 1.35 & -0.96 & -0.54 & -0.42
\end{tabular}

${ }^{a}$ Obtained from DPV or CV measurements. ${ }^{b}$ Wavelength of lowest energy absorption maximum or of maximal PL in dilute toluene solutions. ${ }^{c}$ Energy corresponding to maximal PL emission of molecules in solution or dispersed in a host matrix at low concentrations. ${ }^{39}{ }^{d}$ Difference between the LUMO energy of the A and HOMO energy of the D. ${ }^{e} \Delta G_{\mathrm{CT}}=E_{\mathrm{DA}}-E_{\text {optgap }}$ (D). ${ }^{f} \Delta G_{\mathrm{ET}}=E_{\text {opt.gap }}$ (A) $-E_{\text {opt.gap }}$ (D). ${ }^{g}$ IF-TIPS exhibited no measurable PL emission; the optical gap was estimated from the time-dependent density functional theory (TD-B3LYP/6-311+G(d,p)//B3LYP/6$31 G(d))$.

Table 2. Electrochemical, Crystallographic, Photoluminescent, and Photoconductive Properties of Films

\begin{tabular}{|c|c|c|c|c|c|}
\hline material & $\begin{array}{l}\Delta \mathrm{LUMO} \\
\mathrm{eV}\end{array}$ & volume of $R$ (volume/molecule), & $\begin{array}{l}E_{\mathrm{CT}}\left(E_{\mathrm{DA}}\right) \\
\mathrm{eV}^{b}\end{array}$ & 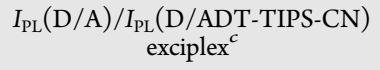 & $t_{\mathrm{ph}, \max }(\mathrm{ns}) \underset{\mathrm{cm}^{d}}{20}(100), \mathrm{kV} /$ \\
\hline pristine ADT-TES-F & & $204(807)$ & & & $<0.6(<0.6)$ \\
\hline \multicolumn{6}{|l|}{ D/A composites } \\
\hline ADT-TIPS-CN & 0.44 & $278.5(1051)$ & $1.86(1.86)$ & 1 & $<0.6(<0.6)$ \\
\hline Pn-F8-NODIPS & 0.53 & $402.5(1246)$ & $1.72(1.76)$ & $0.064 \pm 0.004$ & $3.3(<0.6)$ \\
\hline Pn-F8-TCHS & 0.54 & 469.2 & $1.75(1.77)$ & $0.021 \pm 0.001$ & $2.4(<0.6)$ \\
\hline Pn-F8-TIPS & 0.55 & 278.5 (988) & $1.72(1.75)$ & $0.21 \pm 0.03$ & $<0.6(<0.6)$ \\
\hline Hex-F8-TCHS & 0.65 & $469.2(1580)$ & $(1.65)$ & & $2.2(<0.6)$ \\
\hline PCBM & 0.65 & $(1053-1948)^{e}$ & $(1.65)$ & & $2.8(<0.6)$ \\
\hline IF-TCHS & 0.92 & $469.2(1209)$ & $(1.38)$ & & $3.3(<0.6)$ \\
\hline IF-TIPS & 0.95 & 278.5 (928) & $(1.35)$ & & $<0.6(<0.6)$ \\
\hline
\end{tabular}

${ }^{a}$ Volume of a side group R calculated from crystallographic data. The number in parentheses is a unit cell volume (from CIF files) divided by the number of molecules in the unit cell. ${ }^{b}$ Energy of the CT state obtained from peak PL emission from the exciplex. The value in parentheses is the difference between the LUMO energy of the A and HOMO energy of the D. ${ }^{c}$ Exciplex PL obtained from integrated exciplex PL spectra in various $\mathrm{D} / \mathrm{A}$ composites with respect to that in the composite with ADT-TIPS-CN acceptor. Error reflects sample-to-sample variation. ${ }^{d}$ Time at which the transient photocurrent reached maximum at the applied $E$ field of $20 \mathrm{kV} / \mathrm{cm}(100 \mathrm{kV} / \mathrm{cm}) .{ }^{e}$ Values depend on the solvent used for sample preparation and were taken from ref 51 .

\section{EXPERIMENTAL PART}

2.1. Materials. In all $\mathrm{D} / \mathrm{A}$ composites, a high-performance ADT-TES-F derivative (Figure 1a.1) was used as the donor. This ADT derivative exhibited high charge carrier (hole) mobilities ( $>1.5 \mathrm{~cm}^{2} /(\mathrm{Vs})$ in thin-film transistors), ${ }^{36,37}$ high photoconductive gains, and relatively strong photoluminescence (PL) in solution-deposited polycrystalline films. ${ }^{38,39}$ To explore effects of D and A HOMO and LUMO energy offsets, we chose multiple acceptors with various HOMO and LUMO energies that, for example, yielded LUMO offsets ( $\triangle$ LUMO) ranging between 0.44 and $0.95 \mathrm{eV}$ (Figure $1 \mathrm{~b}$ and Tables 1 and 2 ). This range is of interest, as numerical modeling predicted the highest PCEs at a $\triangle \mathrm{LUMO}$ of $\sim 0.55 \mathrm{eV}$ and fill factor saturation at $\sim 1 \mathrm{eV}^{6}$ To explore D/A molecular packing effects, different groups of acceptor molecules were chosen, such as pentacene $(\mathrm{Pn})$ and indenofluorene (IF) derivatives, 
which have similar HOMO and LUMO energies but are functionalized with side groups ( $\mathrm{R}$ in Figure 1a) of different sizes that yield different packing motifs in the solid state. ${ }^{40,41}$ In particular, the following acceptor molecules were employed: (i) ADT-TIPS-CN, Figure $1 \mathrm{a} .1 ;^{34,35}$ (ii) three fluorinated Pn derivatives with TIPS, ${ }^{42}$ NODIPS, and TCHS side groups (PnF8-R, Figure 1a.2); (iii) a fluorinated hexacene (Hex) derivative with TCHS side groups (Hex-F8-TCHS, Figure 1a.3); ${ }^{43}$ (iv) two IF derivatives with TIPS and TCHS side groups (IF-R, Figure 1a.5); ${ }^{44,45}$ and (v) PCBM (Figure 1a.4, from SigmaAldrich). HOMO and LUMO energies for molecules under study, measured in solution using differential pulse voltammetry $(\mathrm{DPV})^{38}$ or cyclic voltammetry $(\mathrm{CV}),{ }^{44}$ are shown in Figure 1b. The values for PCBM, which vary considerably in the literature, were taken from the Sigma-Aldrich data sheet and are also consistent with those previously measured by DPV. ${ }^{32}$ Molecular structures for side groups are shown in Figure 2.

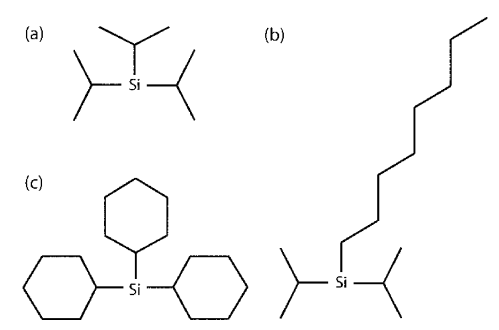

Figure 2. Chemical structure of the side groups R. (a) TIPS, (b) NODIPS, and (c) TCHS.

Optical absorption and PL spectra for molecules in solution are provided in Figure S1 of the Supporting Information (SI) and are summarized in Table 1. Although the exact D and A molecular arrangement at the D/A interface is not known, the approximate volume of the side group $\mathrm{R}$ and/or average volume per molecule calculated from crystallographic data for the $\mathrm{D}$ and A molecules (Table 2) provided a relative measure of separation between the $\mathrm{D}$ and A molecules in the solid state. For example, in composites with Pn acceptors, the largest D/A separation at the $\mathrm{D} / \mathrm{A}$ interface would be expected with large TCHS substituent, followed by NODIPS and TIPS side groups.

2.2. Sample Preparation. In our study, $6 \mathrm{mM}$ solutions of ADT-TES-F in toluene and 2 wt \% acceptor/98 wt \% donor mixtures in toluene were used to drop-cast pristine ADT-TES-F (pristine D) and composite films, respectively. For all drop-cast films, substrates were placed on a hot plate at $\sim 65{ }^{\circ} \mathrm{C}$, and multiple $\sim 10 \mu \mathrm{L}$ drops were dispensed slowly using a pipettor to control film formation over the photolithographically deposited $\mathrm{Cr} / \mathrm{Au}(5 \mathrm{~nm} / 50 \mathrm{~nm})$ interdigitated electrode pairs. Each interdigitated electrode pair consisted of 10 pairs of $1 \mathrm{~mm}$ long and $25 \mu \mathrm{m}$ wide fingers, with a $25 \mu \mathrm{m}$ gap between the fingers of opposing electrodes. This preparation method yielded polycrystalline films, as confirmed by X-ray diffraction (e.g., Figure S2 of the Supporting Information). ${ }^{36,37,46}$

The low concentration of acceptor molecules was chosen to minimize the disruption of film crystallinity ${ }^{47}$ and thus prevent reduction in hole mobility. Additionally, this enabled us to relate the photocurrent dynamics to properties of the CT states while neglecting effects of acceptor aggregation, acceptor domain formation, and electron mobility in the acceptor domains. $^{13}$
2.3. Optical Absorption and PL Measurements. For optical absorption measurements in solution and film, light from a halogen lamp (LS-1, Ocean Optics) transmitted through samples was measured using an Ocean Optics USB2000 spectrometer. Measurements of optical absorption and PL emission in films were conducted on an inverted microscope (Olympus IX-71) with a 10X objective. For PL spectral measurements, films were excited in a wide-field geometry with $532 \mathrm{~nm}$ light (frequency-doubled $\mathrm{Nd}: \mathrm{YVO}_{4}$ laser from Coherent). PL emission was collected through a 560DCLP dichroic mirror (Omega Optical) to filter out scatter at the excitation wavelength into an Ocean Optics USB2000 spectrometer calibrated to a $3100 \mathrm{~K}$ halogen lamp.

$\mathrm{PL}$ lifetime measurements were taken under $400 \mathrm{~nm}$ excitation from a frequency-doubled $80 \mathrm{fs}$ Ti:sapphire laser. A time-correlated single-photon counter (TCSPC) board (PicoQuant TimeHarp 200) was used with a single-photon avalanche photodiode (SPAD - Molecular Photonic Devices) for detection. ${ }^{38}$ Combinations of a 420DCLP dichroic mirror (Omega Optical), a 3RD440LP long pass filter (Omega Optical), and a D740/80× band-pass filter (Chroma Tech.) were used to measure the lifetimes of either ADT-TES-F or exciplex PL. The instrument response function (IRF) $(\sim 200$ ps) was recorded using scattered light from a frosted microscope slide. The PL lifetime decays $\left(I_{\mathrm{PL}}\right)$ were fit with a single-exponential function $\left(I_{\mathrm{PL}} \approx C \exp [-\mathrm{t} / \tau]\right)$ to determine the amplitude $C$ and the lifetime $\tau$.

For electric-field-dependent measurements of optical absorption, PL spectra, and PL lifetimes, voltage was applied to the samples using a Keithley 237 source-measure unit. The measurements described above were performed as a function of applied voltage $(V)$ ranging from 0 to $250 \mathrm{~V}$. The average applied electric field $(E)$ was calculated using $E=V / L$, where $L$ is the gap between the electrodes.

2.4. Transient and Continuous-Wave Photocurrent Measurements. For transient photocurrent measurements, a $355 \mathrm{~nm}, 0.18 \mu \mathrm{J} / \mathrm{cm}^{2}, \sim 500$ ps pulsed excitation (cavity Qswitched frequency-tripled Nd:YAG laser, $44.6 \mathrm{kHz}$, from Nanolase) source was used to illuminate samples from the substrate side. Voltage was applied to samples mounted in custom-made fixtures using a Keithley 237 source-measure unit. Transient photocurrents were measured using either a $50 \mathrm{GHz}$ digital sampling oscilloscope (DSO) (CSA8200/Tek80E01) with a Centellax UAOL65VM broadband amplifier (100 kHz to $65 \mathrm{GHz}$ ) for measurements on nanosecond time scales or a 300 $\mathrm{MHz}$ DSO (Agilent DSO6032A) for measurements on microsecond time scales. The time resolution of the experimental setup was $\sim 0.6 \mathrm{~ns}$, limited by the laser pulse width and jitter. In pristine ADT-TES-F films under these photoexcitation conditions, the photocurrents reached $\sim 175$ $\mu \mathrm{A}$ at $100 \mathrm{kV} / \mathrm{cm}$.

Continuous-wave $(\mathrm{cw})$ photocurrents in films were measured under $532 \mathrm{~nm}$ (frequency-doubled $\mathrm{Nd}: \mathrm{YVO}_{4}$ laser from Coherent) $3 \mathrm{~mW} / \mathrm{cm}^{2}$ or broad-band $\sim 300-400 \mathrm{~nm}$, peaked at $\sim 370 \mathrm{~nm}$ (96000 solar simulator (Newport) with a dichroic mirror (Oriel 81045), a UV band-pass filter (Oriel 81046), and a color glass filter $(\mathrm{BG} 39, \mathrm{CVI})), 2 \mathrm{~mW} / \mathrm{cm}^{2}$ photoexcitation. For both dark and photocurrent measurements, voltage was applied to the samples, and current was measured using a Keithley 237 source-measure unit. Photocurrent was calculated as the difference between the current measured under photoexcitation and the dark current. In pristine ADT-TES-F films under these photoexcitation conditions, the photocurrents 
reached $\sim 40 \mu \mathrm{A}(12 \mu \mathrm{A})$ at $532 \mathrm{~nm}(\sim 370 \mathrm{~nm})$ excitation at $40 \mathrm{kV} / \mathrm{cm}$.

All measurements were conducted at room temperature.

\section{RESULTS AND DISCUSSION}

3.1. Charge versus Energy Transfer: Basic Considerations. To estimate whether charge or energy transfer would be the dominant interaction in D/A composites, we calculated the change in the free energy upon charge $\left(\Delta G_{\mathrm{CT}}\right)$ and energy $\left(\Delta G_{\mathrm{ET}}\right)$ transfer from $\mathrm{D}$ to $\mathrm{A}$ as follows: ${ }^{48} \Delta G_{\mathrm{CT}}=E_{\mathrm{DA}}-$ $E_{\text {opt.gap }}(\mathrm{D})$ and $\Delta G_{\mathrm{ET}}=E_{\text {opt.gap }}(\mathrm{A})-E_{\text {opt.gap }}$ (D). Here $E_{\mathrm{DA}}$ is the difference between LUMO energy of the A and HOMO energy of the $\mathrm{D}$, and $E_{\text {optgap }}(\mathrm{D}$ or $\mathrm{A})$ is the optical gap obtained from the maximal PL emission in the spectra of the ADT-TES-F donor or acceptors, respectively. Table 1 shows $\Delta G_{\mathrm{CT}}$ and $\Delta G_{\mathrm{ET}}$ values as well as their difference, $\Delta G_{\mathrm{CT}}-$ $\Delta G_{\mathrm{ET}}$, calculated for several $\mathrm{D} / \mathrm{A}$ composites. The negative values of the $\Delta G_{\mathrm{CT}}-\Delta G_{\mathrm{ET}}$ were observed for most composites under study. This, however, would not necessarily guarantee that charge transfer dominates over energy transfer in these composites. For example, in a variety of polymer composites, $\Delta G_{\mathrm{CT}}-\Delta G_{\mathrm{ET}}$ of below $-0.35 \mathrm{eV}$ was needed in order for the charge transfer to dominate. ${ }^{48,49}$ This additional energy of $\sim 0.35 \mathrm{eV}$ was attributed to the energy penalty occurring upon changing from an intra- to interchain exciton. If we apply similar considerations to the case of our smallmolecule $\mathrm{BHJ}$, then energy transfer would be expected to dominate in composites with ADT-TIPS-CN, Pn-F8-R, and Hex-F8-TCHS acceptors and charge transfer in composites with IF acceptors. Previous studies of ADT-TES-F/ADT-TIPS$\mathrm{CN}$ composites identified strong energy transfer between the ADT-TES-F donor and the ADT-TIPS-CN acceptor in the presence of a spacer molecule (which is not expected to interact with either donor or acceptor molecules) such as PMMA. If no spacer molecule was used, however, then the dominant interaction was the formation of the $\mathrm{CT}$ emissive state (exciplex). ${ }^{34}$ Interestingly, in our study, no evidence of energy transfer was observed in any of the composites under study; instead, in all composites, the CT state formation was favored, as discussed in the following sections. This could be due to a smaller energy change from intra- to intermolecular excitons in small-molecule $\mathrm{BHJ}$ so that any negative or even small positive difference $\Delta G_{\mathrm{CT}}-\Delta G_{\mathrm{ET}}$ would be sufficient for CT to dominate, especially in the case of a relatively poor overlap of the donor's PL and acceptor's absorption and large D/A separation (e.g., in the case of the Hex-F8-TCHS acceptor, Figure $\mathrm{S} 1$ of the Supporting Information).

With the above definition of the $\Delta G_{\mathrm{CT}}$, the absolute value of $\Delta G_{\mathrm{CT}}$ is within $0.01 \mathrm{eV}$ of the $\Delta$ LUMO (Tables 1 and 2). Because the exact definition of $\Delta G_{\mathrm{CT}}$ could be ambiguous, ${ }^{27,48}$ in part due to aggregation effects on the optical absorption and PL spectra, ${ }^{39}$ to avoid ambiguity in the following discussions, we will use $\triangle$ LUMO obtained from the DPV or CV measurements instead (Table 2).

3.2. Optical Absorption and PL Properties of $D / A$ Composites. To explore changes in exciton dynamics depending on the acceptor, we measured the optical absorption and PL spectra and PL lifetime decays of films (Section 2.3). Absorption spectra of all composites were similar to those of the pristine D films (Figure S3 of the Supporting Information). Analysis of PL emission in pristine D films (Figure S4(a) of the Supporting Information), attributed to that of disordered $\mathrm{H}$ aggregates, has been previously reported. ${ }^{35,38,39}$ In all composites with A such that $\Delta \mathrm{LUMO}<0.6 \mathrm{eV}$ (i.e., Pn-F8$\mathrm{R}$ and ADT-TIPS-CN), the formation of an emissive CT state (exciplex) was observed in PL data (Table 2 and Figure 3). ${ }^{34,35}$
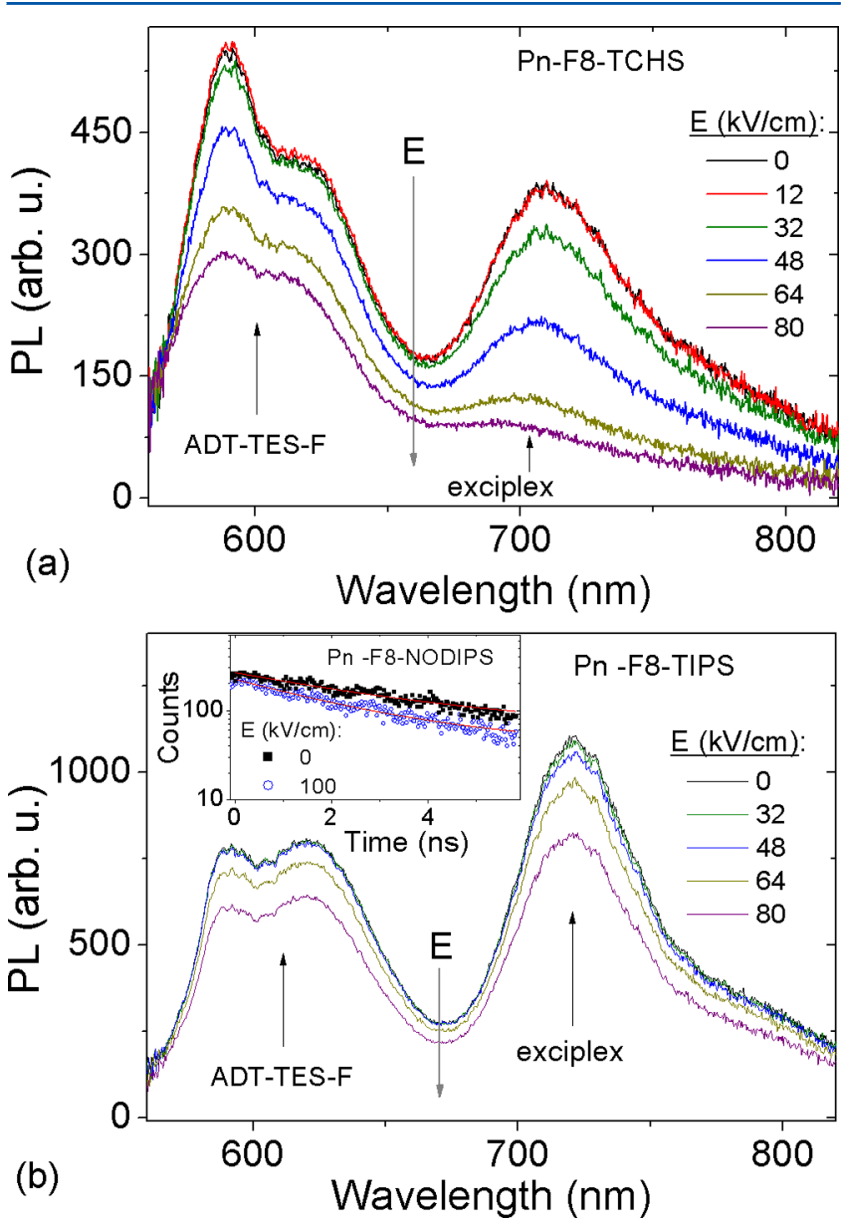

Figure 3. PL spectra of (a) an ADT-TES-F/Pn-F8-TCHS (2\%) film and (b) an ADT-TES-F/Pn-F8-TIPS (2\%) film at various applied electric fields. Spectral contributions corresponding to residual ADTTES-F donor emission and to exciplex emission are indicated. Inset in panel $b$ shows PL lifetime decays of the ADT-TES-F/Pn-F8-NODIPS exciplex in the absence of applied electric field and at $100 \mathrm{kV} / \mathrm{cm}$. Single exponential fits $\left(I_{\mathrm{PL}} \approx C \exp (-t / \tau)\right)$ are also included. The fit parameters: $C=206 \pm 3$ and $\tau=3.43 \pm 0.08$ ns in the absence of the electric field and $C=183 \pm 2$ and $\tau=2.52 \pm 0.05 \mathrm{~ns}$ at $100 \mathrm{kV} / \mathrm{cm}$, which indicates both electric-field-assisted exciplex dissociation (change in $\tau$ ) and dissociation of a precursor state to the exciplex (change in $C$ ).

The exciplex exhibited peak PL emission at an energy $E_{\mathrm{CT}}$ closely matching the energy gap between the LUMO of the A and the HOMO of the $\mathrm{D}, E_{\mathrm{DA}}$ (Table 1) and a longer PL lifetime (e.g., $\sim 3.2-3.4 \mathrm{~ns}, 4.3-4.6 \mathrm{~ns}$, and $\sim 19-22 \mathrm{~ns}$ in composites with Pn-F8-NODIPS, Pn-F8-TIPS, and ADTTIPS-CN acceptors, respectively) than that of ADT-TES-F excitons in pristine D films $(\sim 1.3 \mathrm{~ns}))^{34}$ The energy of CT states $E_{\mathrm{CT}}$ in $\mathrm{D} / \mathrm{A}$ composites has been discussed in the literature in the case of polymer-based blends. ${ }^{27}$ In these materials, $E_{\mathrm{CT}}$ was found to be $\sim 0.3 \mathrm{eV}$ higher than $E_{\mathrm{DA}}$, which was corrected for the difference between the HOMO-LUMO gap $\left(E_{\text {gap }}\right)$ obtained from $\mathrm{CV}$ and $E_{\text {optgap }}$ of the $\mathrm{D}$ and $\mathrm{A}$ obtained from optical measurements. ${ }^{27}$ In our small-molecule $\mathrm{BHJs}$, the $E_{\mathrm{CT}}$ was considerably closer to the $E_{\mathrm{DA}}$ (Table 2), which, similar to observations in Section 3.1, suggests a 
considerably smaller change in Coulomb interaction energy from an intra- to intermolecular exciton.

The strongest exciplex emission was observed in the composite with ADT-TIPS-CN (small D/A separation and the lowest $\triangle$ LUMO of all composites), in which most of the emission originated from the exciplex, whereas that of the $\mathrm{D}$ was almost completely quenched (Figure S5(a) of the Supporting Information). ${ }^{34,35}$ Exciplex emission and quenching of $\mathrm{D}$ emission were considerably weaker in the composites with Pn-F8-R than those with ADT-TIPS-CN (Table 1 and Figure $3)$. In addition, a factor of $\sim 10(\sim 3.3)$ stronger exciplex emission was observed in the composite with Pn-F8-TIPS as compared with that with Pn-F8-TCHS (Pn-F8-NODIPS). This trend strongly correlates with the size of the acceptor's side group $\mathrm{R}$, such that a larger $\mathrm{D} / \mathrm{A}$ separation at the $\mathrm{D} / \mathrm{A}$ interface corresponds to a less emissive exciplex. ${ }^{24}$

In all composite films with A such that $\Delta \mathrm{LUMO}>0.6 \mathrm{eV}$ (0.65-0.95 eV, Table 2), there was no evidence of exciplex emission. Additionally, no signature of energy transfer from $\mathrm{D}$ to A characterized by emission from the acceptor was observed, and only the residual PL from the ADT-TES-F donor was present (e.g., Figures S6 and S7 of the Supporting Information) in these composites. In previously studied ADT-TES-F/ $\mathrm{C}_{60}$ (2\%) D/A films ( $\triangle$ LUMO $=1.45 \mathrm{eV})$, a factor of $5-10$ reduction in the $\mathrm{PL}$ (depending on the film preparation method) was observed, as compared with that in pristine $\mathrm{D}$ films, and attributed to fast photoinduced charge transfer from the $\mathrm{D}$ to $\mathrm{A}$ into charge-separated states, which resulted in a factor of $\sim 3$ improvement in fast charge carrier photogeneration. $^{35,50} \mathrm{~A}$ considerably weaker PL quenching of the $\mathrm{D}$, up to a factor of $\sim 1.6$, was observed in the composites under study with PCBM, Hex-F8-TCHS, and IF-R acceptors. Assuming that the PL quenching of the $\mathrm{D}$ is due to charge transfer from $\mathrm{D}$ to $\mathrm{A}$, this suggests that charge transfer in these composites is considerably less efficient than in those with $\mathrm{C}_{60}$, which could be due to smaller $\triangle$ LUMOs.

To explore the propensity of emissive states to dissociate under applied electric fields ( $E$ fields), we measured PL spectra at various $E$ fields and obtained the PL quenching parameter $Q(E)=1-I_{\mathrm{PL}}(E) / I_{\mathrm{PL}}(0)$, where $I_{\mathrm{PL}}(E)$ and $I_{\mathrm{PL}}(0)$ are integrated PL spectra at the field value $E$ and in the absence of applied electric field, respectively. Spectra were integrated in the PL spectral ranges of the $\mathrm{D}$ and, when applicable, of the exciplex. Considerably higher E-field-assisted quenching $Q$ of both $\mathrm{D}$ exciton and exciplex emission (filled and open symbols in Figure 4, respectively), was observed in composites with larger D/A separations, such as those with PCBM or derivatives that have TCHS side groups, as compared with those with derivatives with TIPS side groups or pristine D films (Figures 3, Figures S4(a) and S5(a) of the Supporting Information). ${ }^{51}$ A reduction in the PL lifetimes, of both the exciplex and $D$ exciton, upon an increase in $E$ field, was observed in all samples. For example, the PL lifetimes of the exciplex in composites with Pn-F8-NODIPS (Pn-F8-TIPS) decreased from $3.4 \mathrm{~ns}$ (4.6 ns) in the absence of $E$ field to $2.5 \mathrm{~ns}(3.8 \mathrm{~ns})$ at $100 \mathrm{kV} / \mathrm{cm}$ (inset of Figure $3 \mathrm{~b}$ ). Under similar conditions, the PL lifetimes of the $\mathrm{D}$ exciton in composites with PCBM (pristine D films) decreased from $1.8(1.3 \mathrm{~ns})$ to $1.2 \mathrm{~ns}(1.1 \mathrm{~ns})$. This confirmed that most of the PL quenching $Q$ in Figure 4 is due to the exciplex and $\mathrm{D}$ exciton dissociation. In the case of the exciplex, the increase in $Q$ with a $D / A$ separation is consistent with a smaller exciplex binding energy resulting from the larger $\mathrm{D} / \mathrm{A}$ separation and thus more efficient dissociation under $E$ fields. ${ }^{17}$

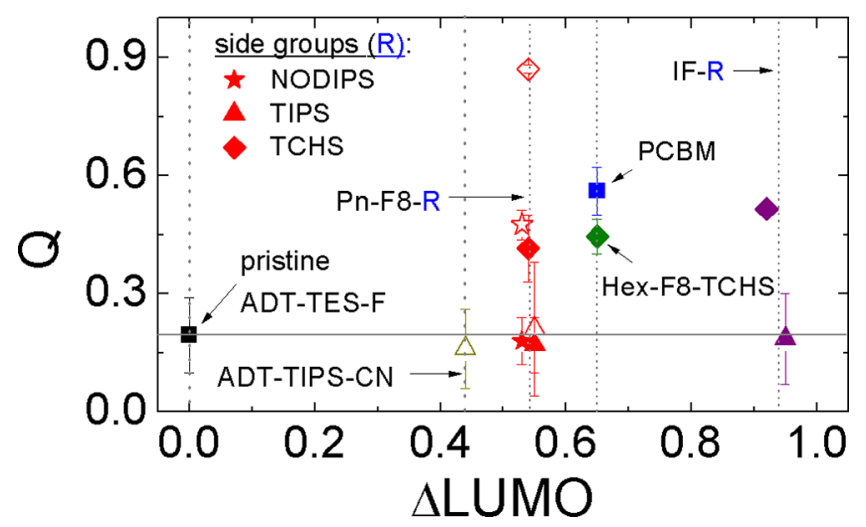

Figure 4. Electric-field-assisted $\mathrm{PL}$ quenching $Q$ at $100 \mathrm{kV} / \mathrm{cm}$ in pristine ADT-TES-F (pristine D) films $(\triangle \mathrm{LUMO}=0)$ and in composites. Filled and open symbols correspond to the $\mathrm{D}$ exciton and exciplex emission, respectively. Error bars reflect sample-to-sample variation. Considerably higher values of $Q$ are observed in composites with larger D/A separation.

The similar trend observed in $Q$ for the $D$ exciton indicates that in composites with large $\mathrm{D} / \mathrm{A}$ separation, excitons on $\mathrm{D}$ molecules near the D/A interface contribute significantly to the $\mathrm{PL}$ and are considerably more prone to dissociation, as compared with D excitons in pristine D films or in composites with acceptors that have TIPS side groups. A reduction in the amplitude of the PL lifetime decays was also observed for both the exciplex and $\mathrm{D}$ exciton. In both cases, it was more pronounced in composites with a larger D/A separation; for example, an amplitude reduction of $\sim 11 \%(<1 \%)$ in composites with the Pn-F8-NODIPS (Pn-F8-TIPS) exciplex and of $\sim 20 \%$ (8\%) in the D exciton in the composite with PCBM (pristine D films) was observed. This suggests that the efficiency of E-fieldassisted dissociation of a precursor state to both the exciplex and $\mathrm{D}$ exciton is also affected by the $\mathrm{D} / \mathrm{A}$ separation.

3.3. Transient Photocurrent. To understand the relationship between the exciton dissociation (both exciplex and D exciton) observed in PL and charge-carrier photogeneration, we measured photocurrents in films under pulsed $(355 \mathrm{~nm}, 500$ ps) photoexcitation as a function of applied $E$ field (Section 2.4). In pristine D films, at all values of applied $E$ field, transient photocurrents $\left(I_{\mathrm{ph}}\right)$ with a sub- $0.6 \mathrm{~ns}$ rise time, limited by the time resolution of the setup, were obtained (Table 2 and Figure S4(b) of the Supporting Information). This indicates fast (most likely sub-30 ps or below $)^{52-55}$ charge-carrier photogeneration, consistent with previous studies of similar films. ${ }^{35,38,53}$ Because charge photogeneration occurred faster than $\mathrm{D}$ exciton dissociation, assessed in measurements of PL lifetime decays, at all $E$ fields, most of the photogenerated carriers contributing to the peak of $I_{\mathrm{ph}}$ originated from the dissociation of a state, which is a precursor to the emissive $\mathrm{D}$ exciton. ${ }^{35}$ After peak photogeneration, the $I_{\mathrm{ph}}$ transient exhibited a fast initial decay, due to carrier trapping and recombination, followed by a slow power-law decay that persisted up to at least $\sim 2 \mu \mathrm{s}$, as in previous studies. ${ }^{50,53}$ In all films, the fast decay component was electric-field-dependent, which is most likely due to fielddependent charge carrier mobility ${ }^{35}$ that results in fielddependent charge carrier trapping and recombination rates. In composites with small D/A separation (acceptors with TIPS side groups), a sub-0.6 ns rise time of the $I_{\mathrm{ph}}$ was observed at all $E$ fields (Table 2 and Figures 5a and 6a), similar to pristine D films. Thus, most of the photogenerated carriers contributing to 


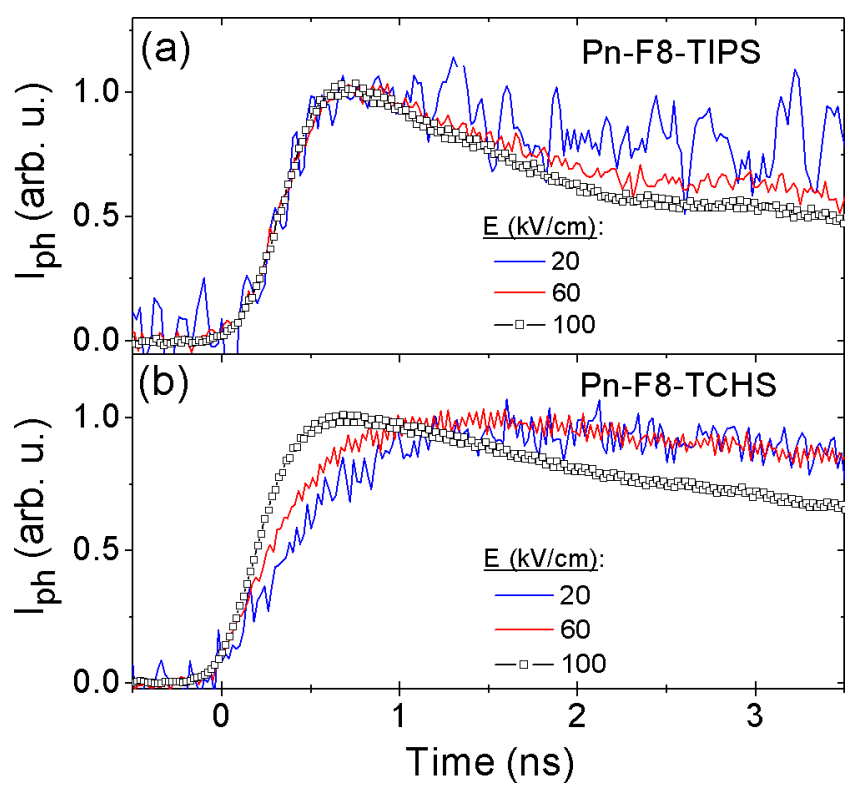

Figure 5. Transient photocurrents $\left(I_{\mathrm{ph}}\right)$ measured under $355 \mathrm{~nm}, 500$ ps pulsed excitation, normalized by their peak values at several applied electric fields in composites with (a) Pn-F8-TIPS and (b) Pn-F8TCHS acceptors.

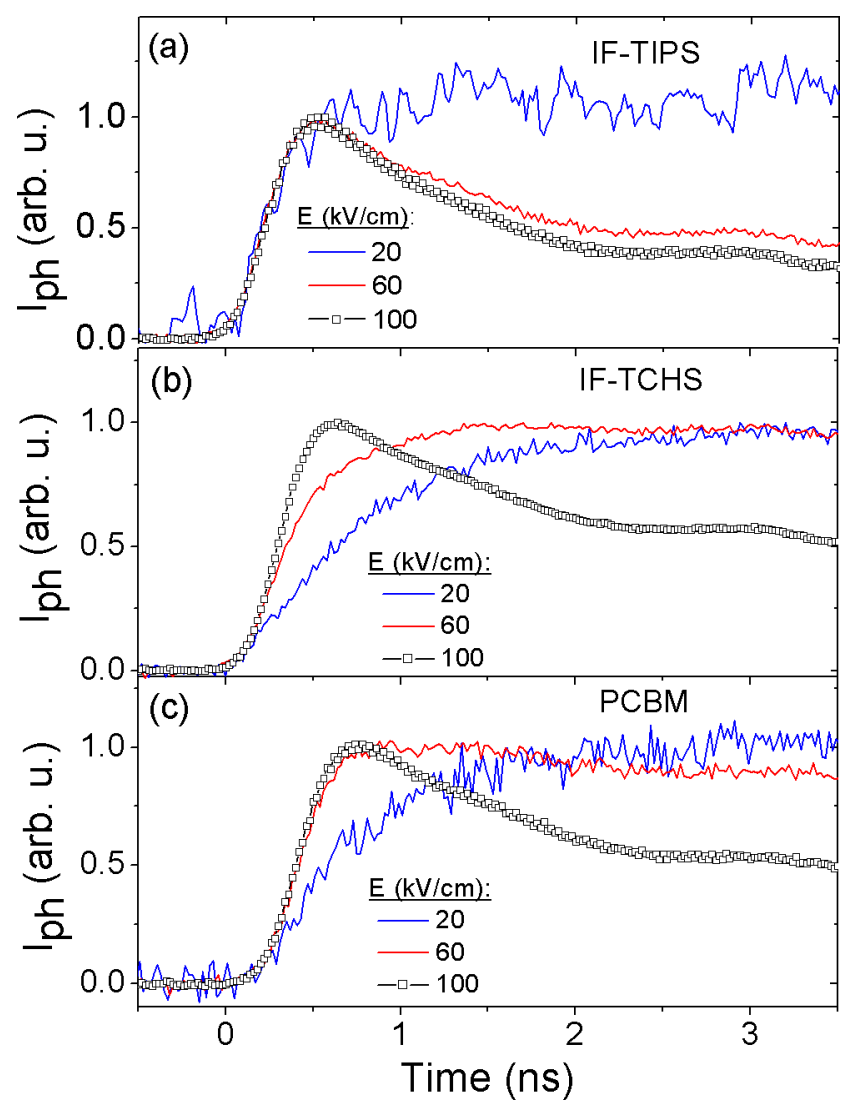

Figure 6. Transient photocurrents $\left(I_{\mathrm{ph}}\right)$ measured under $355 \mathrm{~nm}, 500$ ps pulsed excitation, normalized by their peak values at several applied electric fields in composites with (a) IF-TIPS, (b) IF-TCHS, and (c) PCBM acceptors.

the peak of $I_{\mathrm{ph}}$ were produced by dissociation of a state that is a precursor to the $\mathrm{D}$ exciton, as in pristine $\mathrm{D}$ films, and the contribution of exciplex dissociation to $I_{\mathrm{ph}}$ was small. In contrast, in composites with a larger D/A separation, the rise time of $I_{\mathrm{ph}}$ was highly E-field-dependent (Figures $5 \mathrm{~b}$ and $6 \mathrm{~b}, \mathrm{c}$ and Table 2). For example, in composites with Pn-F8-TCHS or Pn-F8-NODIPS acceptors (Figure 5b), the peak of $I_{\mathrm{ph}}$ at 20 $\mathrm{kV} / \mathrm{cm}$ occurred at times $t_{\mathrm{ph} \text { max }} \approx 2.4$ and $3.3 \mathrm{~ns}$, respectively, consistent with the time scales of exciplex lifetimes in Pn-F8-R composites (e.g., inset of Figure $3 \mathrm{~b}$ ), whereas the charge photogeneration was considerably faster $(<0.6 \mathrm{~ns})$ at $100 \mathrm{kV} /$ $\mathrm{cm}$. Interestingly, at $20 \mathrm{kV} / \mathrm{cm}$, a similarly slow photocurrent rise (with $t_{\mathrm{ph} \text {,max }} \approx 2.2$ to $3.3 \mathrm{~ns}$ ) was observed in composites that did not exhibit any exciplex emission (i.e., those with HexF8-TCHS, PCBM, and IF-TCHS acceptors (Table 2 and Figure $6 \mathrm{~b}, \mathrm{c})$ ). A possible explanation for this behavior is the existence of a nonemissive CT state with a lifetime of several nanoseconds at the $\mathrm{D} / \mathrm{A}$ interface in these composites, similar to that reported in a variety of polymer-based blends. ${ }^{27}$

Regardless of the emission properties of the CT exciton in our composites, the following picture of nanosecond time-scale charge photogeneration emerged. The photoexcitation of the $\mathrm{D}$ results in the formation of a precursor state to the $\mathrm{D}$ exciton, followed by the competition between sub- $0.6 \mathrm{~ns}$ charge-carrier photogeneration and CT exciton formation. ${ }^{56,57}$ At low $E$ fields $(\leq 60 \mathrm{kV} / \mathrm{cm})$, a range that is relevant for photovoltaics, ${ }^{6}$ the $\mathrm{CT}$ exciton formation prevails and is followed by slow charge carrier generation via $E$-field-assisted dissociation. Because the $\mathrm{CT}$ exciton dissociation is more efficient in composites with a larger D/A separation, ${ }^{17}$ a small improvement in charge photogeneration (of up to factor of 2 at $40 \mathrm{kV} / \mathrm{cm}$ at $\Delta \mathrm{LUMO}=0.92 \mathrm{eV}$, depending on the $\Delta \mathrm{LUMO}$, filled symbols in Figure 7) is observed in these composites as compared with

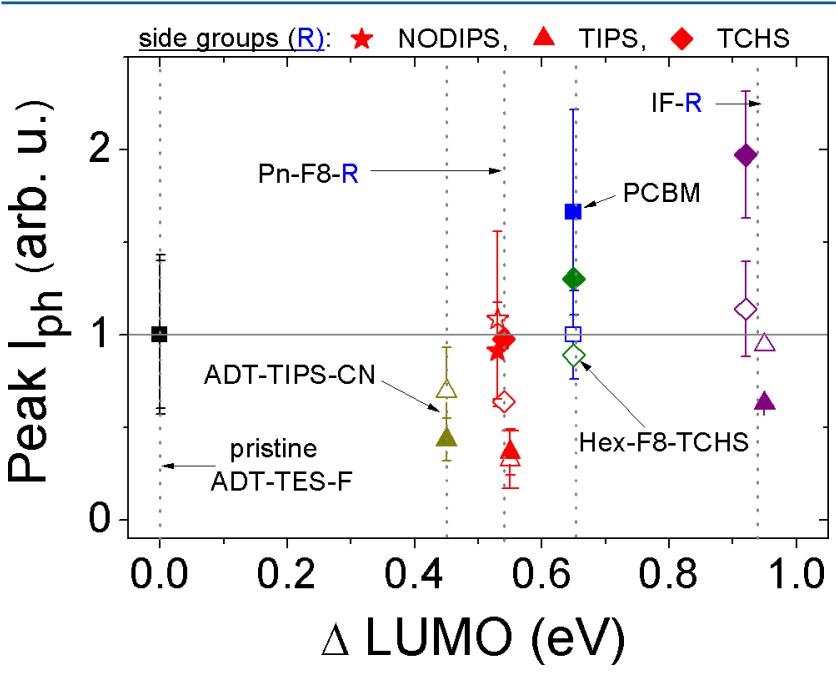

Figure 7. Peak transient photocurrents $\left(I_{\mathrm{ph}}\right)$ obtained in composites at 40 (filled symbols) and $100 \mathrm{kV} / \mathrm{cm}$ (open symbols) under $355 \mathrm{~nm}$, 500 ps excitation, normalized by corresponding values measured in pristine ADT-TES-F (pristine D) films. Error bars correspond to sample-to-sample variation.

pristine $\mathrm{D}$ films. This trend is consistent with previous observations of a factor of 3 increase in the peak of $I_{\mathrm{ph}}$ in $\mathrm{ADT}-\mathrm{TES}-\mathrm{F} / \mathrm{C}_{60}(2 \%)$ composites $(\Delta \mathrm{LUMO}=1.45 \mathrm{eV})$ as compared with pristine D films. ${ }^{50}$ In contrast, the CT exciton dissociation is not efficient in composites with acceptors having TIPS side groups, and thus a reduction in charge photogeneration efficiency is observed in these composites, as compared with pristine D films (Figure 7, filled symbols, 40 $\mathrm{kV} / \mathrm{cm})$. At high $E$ fields $(>60 \mathrm{kV} / \mathrm{cm})$, a range that is relevant, 
for example, for photorefractive applications, ${ }^{5}$ fast carrier photogeneration from the precursor state to the pristine $\mathrm{D}$ and $\mathrm{CT}$ excitons dominates over the $\mathrm{CT}$ exciton formation in all composites, and no increase in charge photogeneration efficiency in composites as compared with pristine D films is observed (open symbols in Figure 7, $100 \mathrm{kV} / \mathrm{cm}$ ).

Figure $8 \mathrm{a}$ shows the effect of the $\mathrm{A}$ on charge-carrier recombination. In all composites with a larger $\mathrm{D} / \mathrm{A}$ separation
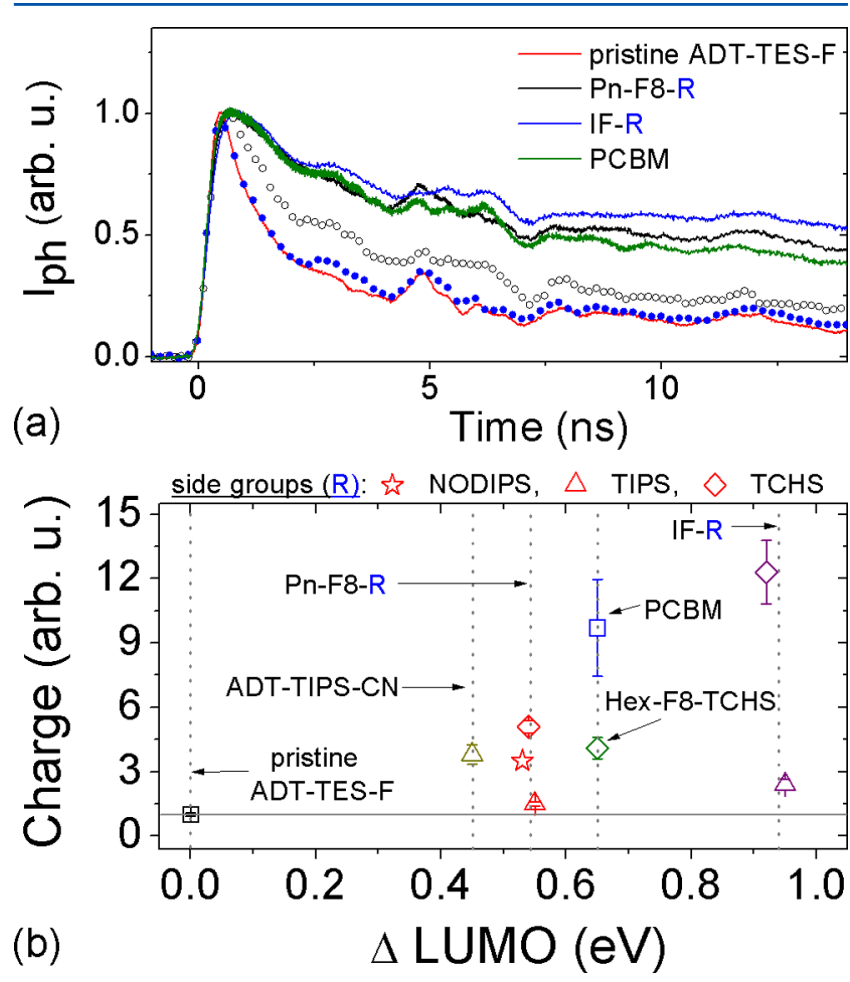

Figure 8. (a) Normalized transient photocurrents measured at 100 $\mathrm{kV} / \mathrm{cm}$ in a pristine ADT-TES-F (pristine D) film (red line) and in composites with Pn-F8-R (black line and open squares for R = TCHS and TIPS, respectively), IF-R (blue line and filled circles for $\mathrm{R}=$ TCHS and TIPS, respectively), and PCBM (green line). (b) Total mobile charge in composites obtained by integrating transient photocurrents, measured under $355 \mathrm{~nm}, 500$ ps pulsed excitation at $80 \mathrm{kV} / \mathrm{cm}$, over $\sim 2 \mu \mathrm{s}$, normalized by corresponding values in pristine ADT-TES-F (pristine D) films. Error bars correspond to sample-tosample variation.

(i.e., with PCBM or derivatives with TCHS or NODIPS side groups), at the same electric field, the initial decay of the transient photocurrent was considerably slower than that in pristine D films or in composites with A that have TIPS side groups, indicative of inhibited charge-carrier recombination. For example, at $100 \mathrm{kV} / \mathrm{cm}$, only $\sim 11 \%$ of initially generated charge carriers remained mobile at $\sim 10$ ns after photoexcitation in the pristine $\mathrm{D}$ films; this number increased to $\sim 45 \%$ in composites with Pn-F8-TCHS and PCBM acceptors and to $53 \%$ in those with IF-TCHS. Figure $8 \mathrm{~b}$ shows the amount of mobile charge obtained by integrating photocurrent transients measured at $80 \mathrm{kV} / \mathrm{cm}$ over the time scale of $\sim 2 \mu \mathrm{s}$ in composites, normalized by those in pristine $\mathrm{D}$ films. In all composites, the inhibited recombination led to a higher total charge as compared with that in pristine $\mathrm{D}$ films, with the highest increase (by a factor of $4-12$ ) in composites with a larger D/A separation (i.e., with PCBM and derivatives with TCHS side groups).
3.4. Cw Photocurrent. Figure 9 shows $\mathrm{cw}$ photocurrents $\left(I_{\mathrm{cw}}\right)$ obtained at $532 \mathrm{~nm}$ and a broad-band 300-400 nm

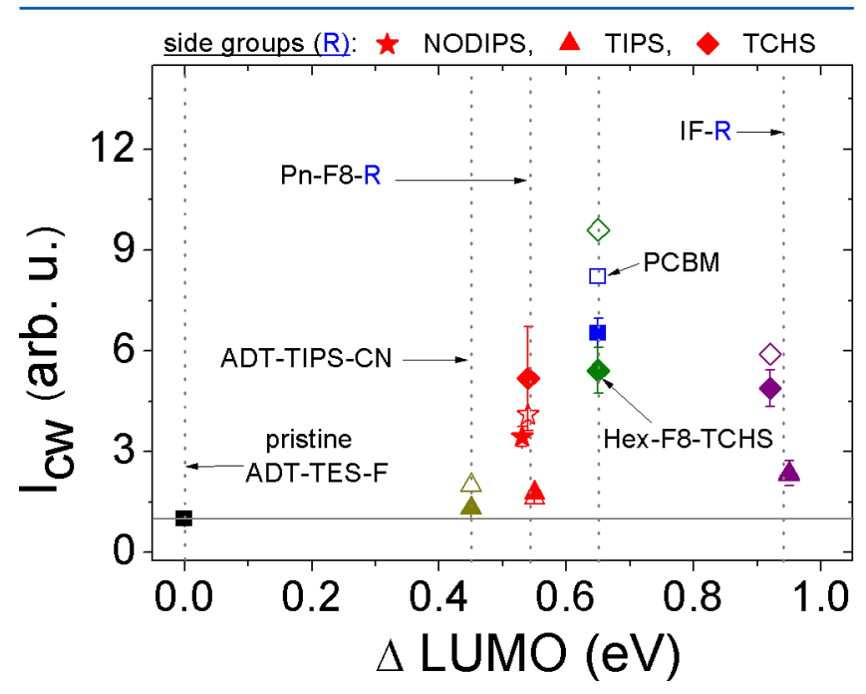

Figure 9. Photocurrents obtained under 532 and $300-400 \mathrm{~nm}$ (peaked at $\sim 370 \mathrm{~nm}$ ) $\mathrm{cw}$ photoexcitation (filled and open symbols, respectively) at $40 \mathrm{kV} / \mathrm{cm}$, normalized by corresponding values measured in pristine ADT-TES-F (pristine D) films. Error bars correspond to sample-to-sample variation.

(peaked at $\sim 370 \mathrm{~nm}$ ) excitation (filled and open symbols, respectively) at an $E$ field of $40 \mathrm{kV} / \mathrm{cm}$ in composites, normalized by those in pristine D films. An increase in $I_{\mathrm{cw}}$ was observed in all composites as compared with pristine D films, with a larger increase (by a factor of 5-10) achieved in composites with a larger $\mathrm{D} / \mathrm{A}$ separation (i.e., those with PCBM or derivatives with TCHS side groups), as compared with that of a factor of 1.8 to 2.5 in composites with smaller D/ A separation (i.e., those with derivatives that have TIPS side groups). In keeping with the insights obtained from timeresolved photocurrents in Figures 7 and 8b, we attribute most of the increase in $I_{\mathrm{cw}}$ in composites to inhibited charge recombination rather than to improved photogeneration efficiency. The overall trends in $I_{\mathrm{cw}}$, at both 532 and 2370 $\mathrm{nm}$ excitation, can be summarized as follows: (i) no particular dependence of $I_{\mathrm{cw}}$ on the $\triangle \mathrm{LUMO}$ in composites with large D/ A separation and a slight increase in $I_{\mathrm{cw}}$ with $\triangle \mathrm{LUMO}$ (by a factor of $\sim 1.5$ from a $\triangle$ LUMO of 0.44 to $0.95 \mathrm{eV}$ ) in composites with small D/A separation and (ii) considerably stronger dependence of the $I_{\mathrm{cw}}$ on the $\mathrm{D} / \mathrm{A}$ separation as compared with effects of the $\triangle$ LUMO. This suggests that it should be possible to optimize the CT properties of BHJs by controlling the molecular arrangement at the interface ${ }^{17,18}$ without a need to further increase the D/A LUMO offset, which is often detrimental to the open circuit voltage in solar cells. ${ }^{6}$

\section{SUMMARY}

In summary, composite films of small molecules with $\triangle$ LUMO of $<0.6$ and $>0.6 \mathrm{eV}$ exhibited exciplex and nonemissive CT state formation, respectively. E-field-assisted PL quenching of the exciplex and of the $D$ exciton dramatically depended on the $\mathrm{D} / \mathrm{A}$ separation. A competition between sub-0.6 ns chargecarrier photogeneration and CT exciton formation was observed, with outcomes depending on the applied $E$ field and on the spatial D/A separation. At low $E$ fields, CT 
formation was dominant, and up to a factor of 2 increase in charge photogeneration efficiency due to CT exciton dissociation was observed in composites with large spatial D/ A separation, as compared with that in pristine D films. At high $E$ fields, the fast charge-carrier photogeneration was dominant in all composites, and no improvement in charge photogeneration efficiency with respect to that in pristine $\mathrm{D}$ films was observed. Dramatic changes in charge carrier recombination dynamics were observed depending on the spatial D/A separation. These contributed to up to a factor of 5-10 improvement in cw photocurrents in composites with large D/ A separation, as compared with those in pristine D films. Our studies show that it is possible to control properties of CT states and their contribution to the photocurrent by optimizing morphology of the $\mathrm{D} / \mathrm{A}$ interface. In particular, both $\mathrm{CT}$ dissociation and charge carrier recombination can be effectively manipulated by adjusting the molecular interaction between the $\mathrm{D}$ and $\mathrm{A}$ by changing the size of the substituent on the $\mathrm{A}$, without needing to increase $\triangle$ LUMO (at least for $\triangle$ LUMO $>0.5 \mathrm{eV}$ ) to improve the photocurrent; this could enable, for example, maximizing the open circuit voltage in solar cells. In applications that rely on applied $E$ fields, it should be possible to manipulate contributions of CT excitons to the photocurrent by changing the $E$ field and thus tune charge photogeneration dynamics and efficiency to satisfy particular requirements.

\section{ASSOCIATED CONTENT}

\section{S Supporting Information}

Synthesis and characterization of IF-TCHS, X-ray diffraction data, optical absorption and PL spectra of molecules and selected composites, and PL spectra and transient photocurrents at various applied electric fields for pristine ADT-TES$\mathrm{F}$ and several composites. The material is available free of charge via the Internet at http://pubs.acs.org.

\section{AUTHOR INFORMATION}

\section{Corresponding Author}

*E-mail: oksana@science.oregonstate.edu.

\section{Notes}

The authors declare no competing financial interest.

\section{ACKNOWLEDGMENTS}

We thank T. Sharf for photolithography of device substrates. This work was supported by NSF (CAREER) program (DMR0748671) to O.O., NSF (CHE-1013032) to M.M.H., NSF (DMR-1035257) to J.E.A., and ONR grant N0014-07-1-0457.

\section{ABBREVIATIONS}

HOMO, highest occupied molecular orbital; LUMO, lowest unoccupied molecular orbital; D, donor; A, acceptor; BHJ, bulk heterojunction; PL, photoluminescence; $\mathrm{CT}$, charge transfer; $\mathrm{cw}$, continuous wave; $\mathrm{ADT}$, anthradithiophene; Pn, pentacene; Hex, hexacene; IF, indeno[1,2-b]fluorene; PCBM, [6,6]phenyl- $\mathrm{C}_{61}$-butyric acid methyl ester; PMMA, poly(methylmethacrylate); ADT-TES-F, fluorinated ADT functionalized with (triethylsilyl)ethynyl side groups; ADT-TIPS-CN, ADT with cyano end groups and functionalized with (triisopropylsilyl)ethynyl side groups; TIPS, (triisopropylsilyl)ethynyl; NODIPS, (n-octyldiisopropylsilyl)ethynyl; TCHS, (tricyclohexylsilyl)ethynyl

\section{REFERENCES}

(1) Forrest, S. R. Nature 2004, 428, 911.

(2) Katz, H. E.; Huang, J. Annu. Rev. Mater. Res. 2009, 39, 71.

(3) Heeger, A. J. Chem. Soc. Rev. 2010, 39, 2354.

(4) Kim, Y.; Ballarotto, M.; Park, D.; Du, M.; Cao, W.; Lee, C. H.; Herman, W. N.; Romero, D. B. Appl. Phys. Lett. 2007, 91, 193510.

(5) Ostroverkhova, O.; Moerner, W. E. Chem. Rev. 2004, 104, 3267.

(6) Clarke, T. M.; Durrant, J. R. Chem. Rev. 2010, 110, 6736.

(7) Walker, B.; Kim, C.; Nguyen, T. Q. Chem. Mater. 2011, 23, 470.

(8) Anthony, J. E. Chem. Mater. 2011, 23, 583.

(9) Roncali, J. Acc. Chem. Res. 2009, 42, 1719.

(10) Lloyd, M. T.; Anthony, J. E.; Malliaras, G. G. Mater. Today 2007, 10, 34.

(11) Sun, Y.; Welch, G.; Leong, W.; Takacs, C.; Bazan, G.; Heeger, A. J. Nat. Mater. 2012, 11, 44.

(12) Mishra, A.; Bauerle, P. Angew. Chem., Int. Ed. 2012, 51, 2020.

(13) Lim, Y. F.; Shu, Y.; Parkin, S. R.; Anthony, J. E.; Malliaras, G. G. J. Mater. Chem. 2009, 19, 3049.

(14) Shu, Y.; Lim, Y. F.; Li, Z.; Purushothaman, B.; Hallani, R.; Kim, J. E.; Parkin, S. R.; Malliaras, G. G.; Anthony, J. E. Chem. Sci. 2011, 2, 363.

(15) Shoaee, S.; Eng, M. P.; Espildora, E.; Delgado, J. L.; Campo, B.; Martin, N.; Vanderzande, D.; Durrant, J. R. Energy Environ. Sci. 2010, 3, 971.

(16) Ohkita, H.; Cook, S.; Astuti, Y.; Duffy, W.; Tierney, S.; Zhang, W.; Heeney, M.; McCulloch, I.; Nelson, J.; Bradley, D. D. C.; Durrant, J. R. J. Am. Chem. Soc. 2008, 130, 3030.

(17) Holcombe, T. W.; Norton, J. E.; Rivnay, J.; Woo, C. H.; Goris, L.; Piliego, C.; Griffini, G.; Sellinger, A.; Bredas, J. L.; Salleo, A.; Frechet, J. M. J. J. Am. Chem. Soc. 2011, 133, 12106.

(18) Beljonne, D.; Cornil, J.; Muccioli, L.; Zannoni, C.; Bredas, J. L.; Castet, F. Chem. Mater. 2011, 23, 591.

(19) Beaujuge, P. M.; Frechet, J. M. J. J. Am. Chem. Soc. 2011, 133, 20009.

(20) Deibel, C.; Strobel, T.; Dyakonov, V. Adv. Mater. 2010, 22, 4097.

(21) Bredas, J. L.; Norton, J. E.; Cornil, J.; Coropceanu, V. Acc. Chem. Res. 2009, 42, 1691.

(22) Zhu, X. Y.; Yang, Q.; Muntwiler, M. Acc. Chem. Res. 2009, 42, 1779.

(23) Paquin, F.; Latini, G.; Sakowicz, M.; Karsenti, P. L.; Wang, L.; Beljonne, D.; Stingelin, N.; Silva, C. Phys. Rev. Lett. 2011, 106, 197401.

(24) Morteani, A. C.; Sreearunothai, P.; Herz, L. M.; Friend, R. H.; Silva, C. Phys. Rev. Lett. 2004, 92, 247402.

(25) Veldman, D.; Ipek, O.; Meskers, S. C. J.; Sweelssen, J.; Koetse, M. M.; Veenstra, S. C.; Kroon, J. M.; van Bavel, S. S.; Loos, J.; Janssen, R. A. J. J. Am. Chem. Soc. 2008, 130, 7721.

(26) Lee, J.; Vandewal, K.; Yost, S. R.; Bahlke, M. E.; Goris, L.; Baldo, M. A.; Manca, J.; Van Voorhis, T. J. Am. Chem. Soc. 2010, 132, 11878

(27) Veldman, D.; Meskers, S. C. J.; Janssen, R. A. J. Adv. Funct. Mater. 2009, 19, 1939.

(28) Pensack, R. D.; Asbury, J. B. Chem. Phys. Lett. 2011, 515, 197.

(29) Devizis, A.; Serbenta, A.; Peckus, D.; Thiessen, A.; Alle, R.; Meerholz, K.; Hertel, D.; Gulbinas, V. J. Chem. Phys. 2010, 133, 164904.

(30) Yin, C.; Kietzke, T.; Neher, D.; Horhold, H. H. Appl. Phys. Lett. 2007, 90, 133502.

(31) Bakulin, A. A.; Rao, A.; Pavelyev, V. G.; van Loosdrecht, P. H. M.; Pshenichnikov, M. S.; Niedzialek, D.; Cornil, J.; Beljonne, D.; Friend, R. H. Science 2012, 335, 1340.

(32) Faist, M. A.; Kirchartz, T.; Gong, W.; Ashraf, R. S.; McCulloch, I.; de Mello, J. C.; Ekins-Daukes, N. J.; Bradley, D. D. C.; Nelson, J. J. Am. Chem. Soc. 2012, 134, 685.

(33) Sanchez-Diaz, A.; Pacios, R.; Munecas, U.; Torres, T.; Palomares, E. Org. Electron. 2011, 12, 329.

(34) Shepherd, W. E. B.; Platt, A. D.; Kendrick, M. J.; Loth, M. A.; Anthony, J. E.; Ostroverkhova, O. J. Phys. Chem. Lett. 2011, 2, 362.

(35) Platt, A. D.; Kendrick, M. J.; Loth, M.; Anthony, J. E.; Ostroverkhova, O. Phys. Rev. B 2011, 84, 235209. 
(36) Park, S. K.; Mourey, D. A.; Subramanian, S.; Anthony, J. E.; Jackson, T. N. Appl. Phys. Lett. 2008, 93, 043301.

(37) Gundlach, D. J.; Royer, J. E.; Park, S. K.; Subramanian, S.; Jurchescu, O. D.; Hamadani, B. H.; Moad, A. J.; Kline, R. J.; Teague, L. C.; Kirillov, O.; Richter, C. A.; Kushmerick, J. G.; Richter, L. J.; Parkin, S. R.; Jackson, T. N.; Anthony, J. E. Nat. Mater. 2008, 7, 216.

(38) Platt, A. D.; Day, J.; Subramanian, S.; Anthony, J. E.; Ostroverkhova, O. J. Phys. Chem. C 2009, 113, 14006.

(39) Shepherd, W. E. B.; Platt, A. D.; Hofer, D.; Ostroverkhova, O.; Loth, M.; Anthony, J. E. Appl. Phys. Lett. 2010, 97, 163303.

(40) Anthony, J. E.; Eaton, D. L.; Parkin, S. R. Org. Lett. 2002, 4, 15.

(41) Anthony, J. E.; Brooks, J. S.; Eaton, D. L.; Parkin, S. R. J. Am. Chem. Soc. 2001, 123, 9482.

(42) Swartz, C. R.; Parkin, S. R.; Bullock, J. E.; Anthony, J. E.; Mayer, A. C.; Malliaras, G. G. Org. Lett. 2005, 7, 3163.

(43) Purushothaman, B.; Park, S. R.; Kendrick, M. J.; David, D.; Ward, J. W.; Yu, L.; Stingelin, N.; Jurchescu, O. D.; Ostroverkhova, O.; Anthony, J. E. Chem. Commun. 2012, 48, 8261.

(44) Chase, D. T.; Fix, A. G.; Rose, B. D.; Weber, C. D.; Nobusue, S.; Stockwell, C. E.; Zakharov, L. N.; Lonergan, M. C.; Haley, M. M. Angew. Chem., Int. Ed. 2011, 50, 11103.

(45) Chase, D. T.; Rose, B. D.; McClintock, S. P.; Zakharov, L. N.; Haley, M. M. Angew. Chem., Int. Ed. 2011, 50, 1127.

(46) Kline, R. J.; Hudson, S. D.; Zhang, X. R.; Gundlach, D. J.; Moad, A. J.; Jurchescu, O. D.; Jackson, T. N.; Subramanian, S.; Anthony, J. E.; Toney, M. F.; Richter, L. J. Chem. Mater. 2011, 23, 1194.

(47) Kleemann, H.; Schuenemann, C.; Zakhidov, A. A.; Riede, M.; Lussem, B.; Leo, K. Org. Electron. 2012, 13, 58.

(48) Veldman, D.; Bastiaansen, J.; Lageveld-Voss, B.; Sweelssen, J.; Koetse, M.; Meskers, S. C. J.; Janssen, R. A. J. Thin Solid Films 2006, 511-512, 581.

(49) Halls, J. J. M.; Cornil, J.; dos Santos, D. A.; Silbey, R. J.; Hwang, D. H.; Holmes, A. B.; Bredas, J. L.; Friend, R. H. Phys. Rev. B 1999, 60, 5721

(50) Day, J.; Platt, A. D.; Ostroverkhova, O.; Subramanian, S.; Anthony, J. E. Appl. Phys. Lett. 2009, 94, 013306.

(51) Rispens, M. T.; Meetsma, A.; Rittberger, R.; Brabec, C. J.; Sariciftci, N. S.; Hummelen, J. C. Chem. Commun. 2003, 2116.

(52) Day, J.; Subramanian, S.; Anthony, J. E.; Lu, Z.; Twieg, R. J.; Ostroverkhova, O. J. Appl. Phys. 2008, 103, 123715.

(53) Day, J.; Platt, A. D.; Subramanian, S.; Anthony, J. E.; Ostroverkhova, O. J. Appl. Phys. 2009, 105, 103703.

(54) Cooke, D. G.; Krebs, F. C.; Jepsen, P. U. Phys. Rev. Lett. 2012, 108, 056603.

(55) Ostroverkhova, O.; Cooke, D. G.; Shcherbyna, S.; Egerton, R. F.; Hegmann, F. A.; Tykwinski, R. R.; Anthony, J. E. Phys. Rev. B 2005, 71,035204 .

(56) Tsutsumi, J.; Yamada, T.; Matsui, H.; Haas, S.; Hasegawa, T. Phys. Rev. Lett. 2010, 105, 226601.

(57) Etzold, F.; Howard, I. A.; Mauer, R.; Meister, M.; Kim, T. D.; Lee, K. S.; Baek, N. S.; Laquai, F. J. Am. Chem. Soc. 2011, 133, 9469. 